\title{
Comparison of 'In-Person' Vs 'Online' Teaching, According To Student Perception; A Descriptive Cross Sectional Study From A Medical School In Sri Lanka
}

Priyantha Julian Perera ( $\square$ priyanthaprr@gmail.com )

Faculty of Medicine, Wayamba University of Sri Lanka

Mithila Manjaree Rajakaruna

Faculty of Medicine, Wayamba University of Sri Lanka

Prabash Sandeep Perera

International Medical University

\section{Research Article}

Keywords: Online teaching, In-person teaching, Medical education, Covid 19, Pandemic

Posted Date: October 1st, 2021

DOl: https://doi.org/10.21203/rs.3.rs-929382/v1

License: (c) (1) This work is licensed under a Creative Commons Attribution 4.0 International License.

Read Full License 


\section{Abstract}

Background: Along with all other human activities, education at all levels has been severely curtailed by the Covid 19 pandemic. Most educational institutions responded to this challenge by shifting their teaching activities from the traditional 'in-person' teaching to the 'online' platform. Though 'online teaching' has been around for some time, it was a novelty at many educational settings. This novelty was eagerly embraced by most of the students, but with time, especially in recourse limited settings student opinion might have altered. This study from a newly established medical school in Sri Lanka, discuss the student perceptions comparing 'in-person' vs 'online' teaching.

Methods: A descriptive cross sectional study was conducted at the Medical faculty of Wayamba University of Sri Lanka, between 01.08. 21 and 31.08.21. Medical students currently studying in second and third years, had experienced both 'in-person' and 'online teaching'. They were sent a questionnaire, in the form of a google form. Questionnaire compared 'in-person' vs 'online' teaching, with regard to different aspects of teaching and teacher- students interactions. Z score for comparing proportions was used to assess statistical significance, which was set at $95 \%$ confidant level.

Results: Out of 145 google forms sent out, 133 were returned fully completed. Irrespective of the mode of delivery of lessons, there was no significant difference in student's student active participation or ability to understand contents. However, attendance at lessons, ability to focus during a lessons, and teacher's enthusiasm during the activity were perceived significantly higher during 'in-person' teaching compared to online teaching. A statistically significant number of students had a better overall impression about 'inperson' teaching than 'online' teaching. However, majority of students preferred online teaching to continue along with 'in-person' teaching as a highbred system.

Conclusions: Majority of students wanted 'online' teaching to continue even after pandemic is over, though there are some shortcomings related to 'online' teaching. Educational institutions should constantly evaluate their online teaching program to identify the strengths and shortcomings. Regular student and teacher feedback will be useful in this regard. A highbred system of education, combining online and in-person teaching is recommended for the future.

\section{Background}

World Health Organization on 11.03. 2020, declared 'Novel Corona Virus (COVID 19) outbreak' is likely to result in a pandemic ${ }^{1}$. The ongoing pandemic may not be the worse, human race has ever faced, but the worse in recent times. The pandemic has not left a single walk of life unaffected. Apart from health issues, there are significant impacts on social, economic, political, faiths, sports, entertainment, leisure activities and education. Compared to pandemics in the history, the present Covid 19 pandemic appeared at a time when human race was marching forward rapidly, exploring even the universe for resources. The pandemic brought in abrupt restrictions to all human activities, making him left stunned. 
Other than health, the most significant impact has been on the education. Throughout the globe, the pandemic has badly affected education from nursery to post graduate studies, and Sri Lanka is no exemption. With onset of the pandemic, traditional educational system designed mainly to deliver 'inperson' was no longer possible; an urgent shift towards distant learning was indicated. Sri Lanka is a low middle income country, with a per capita income of 3,852 US\$, in $2019^{2}$. Rural population of Sri Lanka is estimated at $77.4 \%{ }^{3}$. However, the high mobile phone usage in Sri Lanka is a big advantage which can be targeted in delivering 'online teaching'. According to telecommunication regulatory commission statistics in Sri Lanka, by December 2020 the mobile cellular subscriptions per 100 inhabitants was $131.1^{4}$.

The concept of 'Electronic learning' also known as "e-learning" or 'online learning 'originated in mid 1990s, with the internet usage becoming widespread. With onset of the Covid pandemic, 'online teaching' gathered momentum than ever before. Teaching activities in nurseries to universities shifted from the traditional teaching methods to 'online', and became popular within a short period. However, when it came to 'online' teaching in medical schools, the main obstacle was providing clinical training. Though innovative methods have been tried, nothing could replace the training a medical student obtain by interacting directly with patients. Thus, most medical schools in Sri Lanka has adopted a strategy of delivering the theoretical teaching 'online', while allowing full day clinical training, as and when it was possible.

Many studies conducted to evaluate 'online learning' have reported positive evidence towards it. In a study from College of Medicine in Qassim, students obtained better grades when teaching was conducted 'online', than 'in-person' ${ }^{5}$. A systematic review of studies that compared classroom learning vs online learning, has shown equal or higher motivation among students to attend online sessions ${ }^{6}$. Online activity conducted for surgical undergraduates in Sri Lanka has revealed that online teaching with a novel structure is feasible in a resource limited setting, and could enhance the clinical interest in students ${ }^{7}$.

Even a well-structured new teaching modality is of little value, without student acceptance. A study from Saudi Arabia indicated, synchronized online classes were well-accepted by medical students ${ }^{8}$. A Croatian study revealed most health science University students were satisfied with exclusive e-learning, as well as their personal and institutional adjustments towards it ${ }^{8}$.

Availability of adequate resources in educational institutions to deliver and availability of IT facilities for students, are major factors for a successful online teaching program. In a resource limited settings these factors can be crucial. A study from the South Eastern University of Sri Lanka, reveals that the university encountered many challenges delivering lessons and suggest the university should focus on a hybrid education system ${ }^{9}$. Due to COVID 19 pandemic, Sri Lankan Universities have been closed for nearly two years. However, during this period medical schools functioned from time to time for brief spells. Sri Lankan medical schools have made a remarkable and rapid transition to online education, and all 
internet providers in Sri Lanka are providing free internet access toward university servers during the pandemic ${ }^{10}$.

There are no reported studies comparing perceptions of Sri Lankan medical students about learning 'online' vs 'in-person'. In this paper we present findings of a study conducted at the faculty of Medicine, Wayamba University of Sri Lanka (WUSL). Perceptions of students on different aspects of learning, comparing 'online' vs, 'in-person' teaching is presented.

\section{Methodology}

\section{Study design}

A descriptive cross-sectional study was conducted between 01.08. 21 to 31.08 .21 , to determine the perceptions of medical students of WUSL regarding 'online' vs in 'person' teaching.

\section{Study setting}

Faculty of Medicine of the Wayamba University of Sri Lanka was established in 2018, and presently has three batches studying in it. Due to the pandemic the academic activities of faculty were disrupted since March 2020. Online teaching was commenced via zoom, from April 2020 onwards. Therefore, first two batches had 'in-person' as well as 'online' teaching, but the third batch has had only online teaching. Therefore, only first two batches were included for this study. Apart from a few practical sessions and lectures conducted during brief periods when Faculty was kept open, almost all teaching activities during the pandemic were via the zoom.

\section{Study population and sample selection}

All 145 students belonging to the first two batches of the faculty were invited to participate, without any selection.

\section{Data Collection and conduct of the study}

Due to restrictions implemented by the national Covid prevention guidelines, the data collection was via online platform using Google Forms. Google form contained questions with multiple responses and participants were instructed to select the best answer. Participants were invited via an email, with a link to access the Google form. A document containing description and purpose of the study was displayed to the participants initially. Student who wished to participate in the study were instructed to fill the consent form which was also included. Willingness to participate was indicated by selecting the 'accept' option. Only those who selected the accept option were able to continue with the questionnaire. Attendance at teaching sessions, ability to focus during teaching, ability to understand contents, active student participation, teacher's enthusiasm and overall impression was assessed. For each component, students were instructed to indicate whether it was same with both forms of teaching, better with online teaching or better with in-person teaching. Students were also instructed to indicate their views about continuing online teaching once the pandemic was over, and the weightage of each component they suggest. 


\section{Data analysis}

Data analysis was through Google form analyzer, which generates graphs and tables also. Z score for proportions was used to assess the statistical significance. Significant level was set at $95 \%$.

\section{Ethical issues}

Ethical approval to conduct the study was obtained from the Ethics review committee of the faculty of Medicine, Wayamba University of Sri Lanka. Administrative clearance to conduct the study was obtained from the Dean of the faculty of medicine WUSL. Participation in the study was voluntary and participants selecting the 'accept' option was deemed as the consent to participate in the study (vide supra). Participants were informed about the liberty to withdraw from the study at any stage or refrain from answering any number of question. No attempts were made to identify any student, whether they responded or not.

\section{Results}

Out of 145 students who were sent google forms, 133 students responded, giving a high a response rate of $91.7 \%$.

\section{Attendance at teaching sessions}

Student attendance at learning sessions is an important factor for any successful teaching program. Figure 1 compares attendance of students, depending on the mode of teaching. Statistically significant proportions of students (46.6\%), declared better attendance during in-person teaching sessions, compared to online sessions $(p=.013)$.

Figure 2 compares the student attendance as a percentage of total number of teaching sessions conducted. Accordingly, 60 students had 100\% attendance at in-person teaching activity, while only 29 had $100 \%$ attendance at online teaching.

\section{Ability to focus during teaching sessions}

Majority of students (50.4\%) stated they were more focused to the teaching activity, when it was delivered in-person than online. The Fig. 3 depicts the ability of students to focus, depending on the delivery mode of lessons. The difference in ability to focus was statistically significant $(p=.012)$

\section{Ability to understand the contents of a teaching sessions}

A slightly higher percentage of students mentioned they could understand contents of a teaching activity better, when delivered in-person than online (Fig. 4). This difference was not statistically significant ( $p$ $=.41)$.

\section{Active student participation during teaching activity}


Teacher- student interactions during a teaching session play an important role by keeping students focused on the learning activity and raising the enthusiasm of the teacher. 'Online' teaching is often challenging for teachers because unlike during in-person lessons, teacher cannot visualize his students. However, student opinion was almost equally divided with this regard. Figure 5 depicts the distribution of views of students with regard to student participation.

\section{Student opinion on teachers' enthusiasm during teaching session}

Enthusiasm shown by the teacher during a teaching session is of paramount importance for successful learning, as it helps students to remain focused to the learning activity. Majority of students (45.1\%) did not think there was a difference in teacher enthusiasm during learning sessions depending on the mode of teaching. Teacher enthusiasm was more during in-person teaching according $39.1 \%$ students, while $15.8 \%$ felt otherwise (Fig. 6). This difference was statistically significant $(p=.027)$

\section{Overall impression}

Overall perception of the majority (50.4\%) was, teaching 'in-person' is better, but $31.6 \%$ felt otherwise (Fig. 7). This difference in proportions was statistically significant $(p=.026)$

\section{Student opinion on continuing online teaching, after the epidemic is over}

Students were questioned on their willingness to continue 'online' teaching, combined with 'in-person' teaching once the Covid epidemic was over. The results were; $15.8 \%$ strongly agree, $35.3 \%$ agree, $29.3 \%$ neutral and $9.8 \%$ each disagree or strongly disagree (Fig. 8). Thus statistically significant number was of the view that, online teaching activity should continue at least as a part of future teaching activities. ( $p$ $=.002)$

\section{If a highbred system is established weightage of each mode of teaching}

When questioned "if a hybrid program is implemented combining two modes of teaching, what should be the composition of online and in-person activities", student responses were; Online > in-person $34.6 \%$, inperson $>$ online $32.3 \%$, online $=$ in-person $26.3 \%$ (Fig. 9) .

\section{Discussion}

On contrary to most studies available in medical literature which indicate a positive impression towards online teaching results, of our study paints a mixed picture. According to this cohort of students, irrespective of the mode of teaching there is no difference in the ability to understand contents of a lesson or in student participation during an activity. However, attendance of students, ability to focus, and 
teacher's enthusiasm during teaching were significantly high during in-person teaching than online teaching. Overall impression too was in favor of 'in-person' teaching.

One reason for this discrepancy between results of our study and previous reported studies may be the timing. Most reported studies in the literature were conducted during early stages of the epidemic $c^{5,7,8,9}$. Naturally, when a novel and dynamic activity like online teaching is introduced there is lot of enthusiasm initially, which might fall off with time. Some of the reported studies ${ }^{6}$ were conducted prior to the pandemic, when both 'online' and 'in-person' activities were conducted in parallel. This emphasize the importance of keeping teaching pattern changing from time to time and innovating new methods to maintain students interest, if we have to continue mainly with online teaching for some more time.

The reason for significant number of students expressing reduced ability to focus during online sessions may related to connectivity issues. Frequent interruptions during zoom sessions, due to intermittent disconnection of internet is common in Sri Lanka, especially in remote areas. This is more often during periods of high internet usage. When a student gets disconnected during a lesson and rejoins, he will find difficulty following rest of the lesson. Scheduling the teaching timetable, avoiding the rush hours would alleviate this issue to certain degree.

Being at home environment during the lessons, with frequent disturbances from surrounding activates and noises will affect the ability of student to focus on the lesson. The student not been under direct supervision of the teacher also may be contributory factors. Some students join online classes via smart phones, with a small viewing screen. Thus students might face difficulties in reading if the font sizes used are too small. Paying attention to facts like these will help to improve the outcome from online teaching.

With regard to student perception of teacher enthusiasm, it was also better with in-person teaching. This may be because during 'online' teaching only an image or a video of the teacher is seen by the students. Some 'online' teaching is in the form of dubbed, power point presentations. If teachers use novel methods to deliver lessons, prepare attractive presentations, try to interact with students frequently; students will feel the enthusiasm in the teacher, which will make a big impact on student learning.

One reason for students not participating actively during lessons is the phobia of speaking in front of an audience. One would expect it to be better with online teaching, because phobia of speaking is eliminated. However, students did not feel a difference in active participation during lessons depending on mode of teaching.

Amidst of these limitations, majority of students wanted 'online teaching' to continue even after the pandemic is over. However, the opinion was divided on what should be the proportion between 'online' and 'in-person' teaching. Educational institutions should consider these facts on individual basis to come up with a carefully structured educational program considering all aspects, including student perspectives. 


\section{Conclusions And Recommendations}

Majority of students are of the opinion that online teaching should be continued even after ending of the pandemic, even though there are shortcomings. Educational institutes should evaluate their 'online' teaching program on regular basis to identify the strengths and shortcomings. Student and teacher feedback will be useful in this regard. Developing a highbred system combining the 'online' and 'in-person' teaching, catering the educational requirements of the individual study course is recommended.

\section{Abbreviations}

ERC - Ethics review committee

WUSL - Wayamba University of Sri Lanka

\section{Limitations}

Recall bias and subjectiveness of the data obtained are the main limitation of this study.

\section{Declarations}

\section{Ethics approval and consent to participate}

All methods were carried out in accordance with relevant guidelines and regulations. Ethical clearance was obtained from the ERC of the faculty of Medicine WUSL. Administrative clearance was obtained from the Dean of the medical faculty of WUSL (Ref. No. PW/2021/07/01). Participation in the study was voluntary; no intensives for participants, no repercussions towards non-responders. Participants indicated the consent to participate by selecting the 'accept' option in the google form, and only the students who consented could visualize the google form with questions. Participants had the liberty to leave any question unanswered or withdraw altogether even though consented at the beginning. The google form did not contain any item that would reveal the identity and no other attempts were made to identify the participants.

\section{Consent for publication}

Not applicable

\section{Data availability statement}

All data generated and analysed during this study, and pertaining to this manuscript are included here. Any datasets used and analysed pertaining to this manuscript are available from the corresponding author on reasonable request.

\section{Competing interest}


All authors declare no competing interest.

\section{Funding}

No funds were obtained to conduct the study.

\section{Author contributions}

PJP, was involved in conceptualization, planning, development of the protocol, data analysis, and writing the manuscript. All authors have read and approved the manuscript.

MMJ, was involved in planning, data collection, development of the protocol, data analysis, and writing the manuscript.

PSP, was involved in planning, development of the protocol, data analysis, and writing the manuscript.

\section{Acknowledgments}

We would extend our gratitude to the Dean of the medical faculty of WUSL and all students who took their time off to respond.

\section{References}

1. The World Health Organization (WHO) on March 11, 2020, has declared the novel coronavirus (COVID-19) outbreak a global pandemic (1)

2. Sri Lanka GDP Per Capita 1962-2021 | MacroTrends. Available at www.macrotrends.net/countries/LKA/sri-lanka/gdp-per-capita

3. Census of Population and Housing Sri Lanka 2012 Available at www.statistics.gov.lk/PopHouSat/CPH2011/Pages/Activities/Reports/SriLanka.pdf

4. Telecomminication Regulatory Commision. Statistical Over View Report [Internet]. Colombo; 2020. Available from: https://trc.gov.lk/images/pdf/StatisticalOverViewReportQ220212607.pdf.

5. Elzainy A, El Sadik A, Al Abdulmonem W. Experience of e-learning and online assessment during the COVID-19 pandemic at the College of Medicine, Qassim University. J Taibah Univ Med Sci. 2020 Dec; 15(6): 456-462. doi: 10.1016/j.jtumed.2020.09.005

6. Sinclair PM, Kable A, Levett-Jones T, Booth D. The effectiveness of Internet-based e-learning on clinician behaviour and patient outcomes: A systematic review. Int J Nurs Stud. 2016 May;57:70-81. doi: 10.1016/j.jnurstu.2016.01.011. Epub 2016 Feb 4. PMID: 27045566.

7. Chandrasinghe PC, Siriwardana RC, Kumarage SK et.al. A novel structure for online surgical undergraduate teaching during the Covid-19 pandemic. BMC Med Educ. 2020 Sep 22;20(1):324. doi: 10.1186/s12909-020-02236-9. PMID: 32962691; PMCID: PMC7506821 
8. Aldamegh M, Al-Nafeesah A, Alkhalifah A, Al-Wutayd O. The sudden transition to synchronized online learning during the Covid-19 pandemic in Saudi Arabia: a qualitative study exploring medical students' perspectives. BMC Med Educ. 2020 Aug 28;20(1):285. doi: 10.1186/s12909-020-02208-Z. PMID: 32859188; PMCID: PMC7453686

9. Puljak L, Čivljak M, Haramina A, Mališa S, et.al.. Attitudes and concerns of undergraduate university health sciences students in Croatia regarding complete switch to e-learning during Covid-19 pandemic: a survey. BMC Med Educ. 2020 Nov 10;20(1):416. doi: 10.1186/s12909-020-02343-7. PMID: 33167960; PMCID: PMC7652670.

10. Hayashi R, Garcia M, Maddawin A, Hewagamage, K. P. "Online Learning in Sri Lanka's Higher Education Institutions during the COVID-19 Pandemic," ADB Briefs, NO. 151 September 2020 p. 12. Available at- https://www.adb.org/sites/default/files/

\section{Figures}

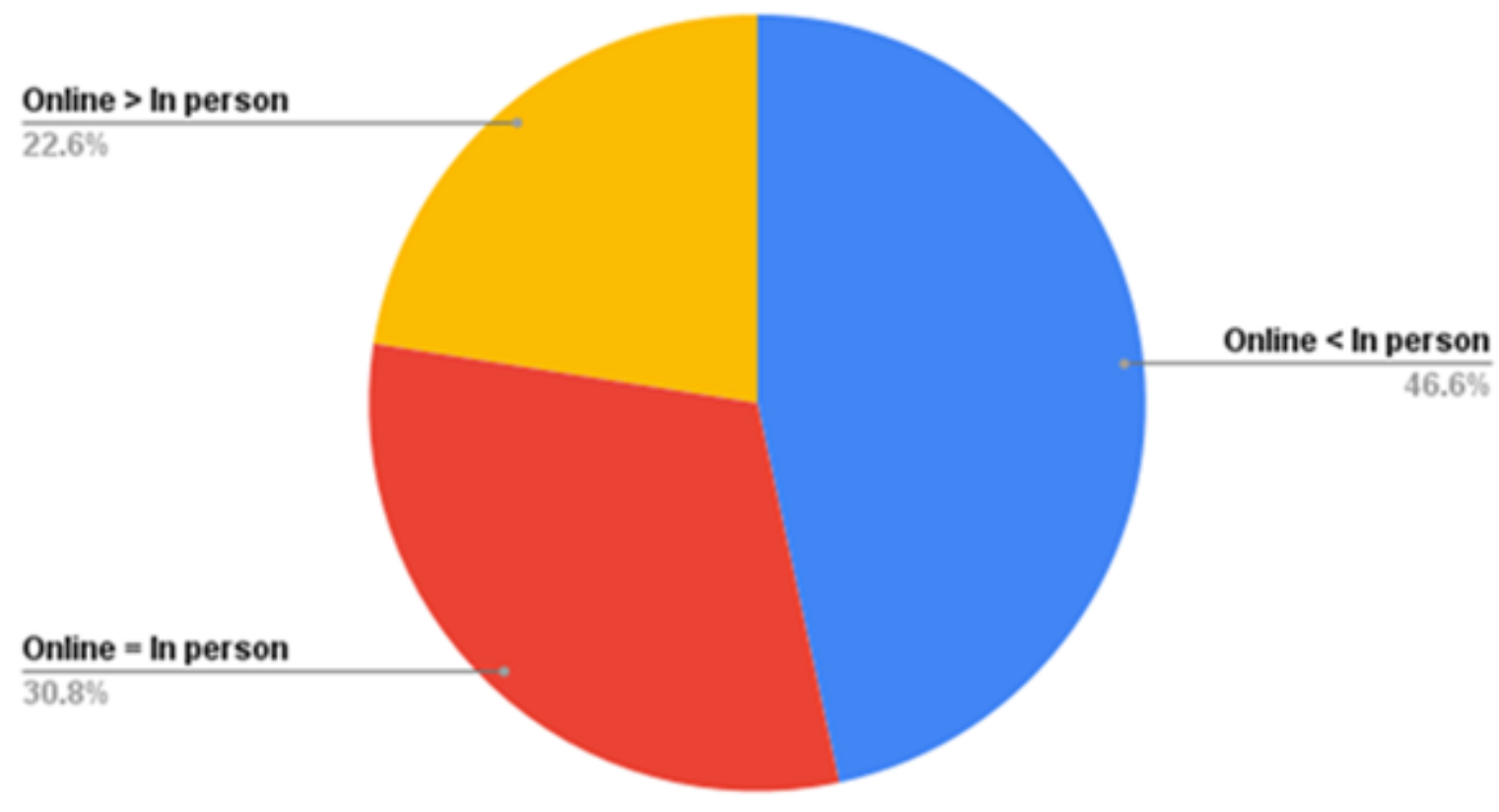

\section{Figure 1}

Comparison of attendance during in-person and online teaching 
Online lecture attendance $\square$ Inperson lecture attendance 100

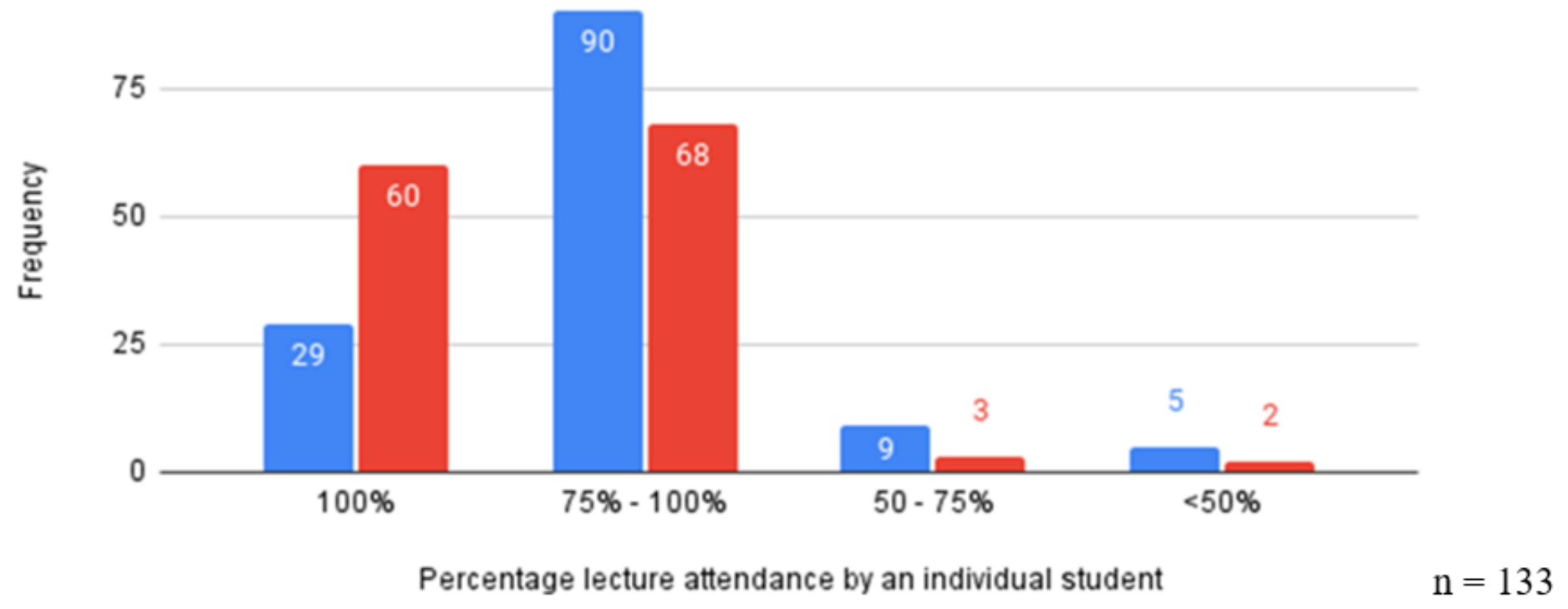

Figure 2

Distribution of student attendance according to the type of teaching activity

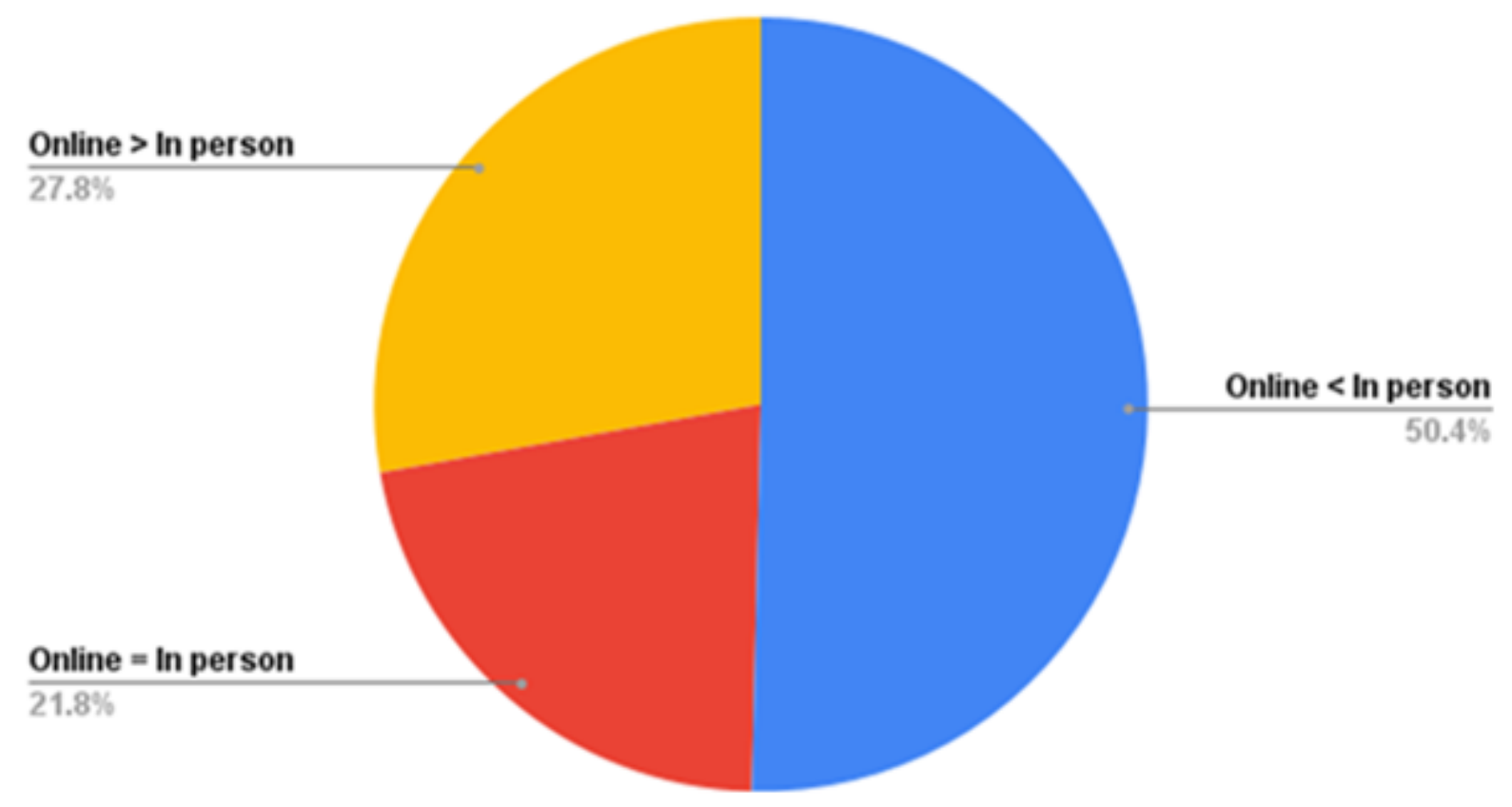

Figure 3

Ability to focus during teaching sessions 


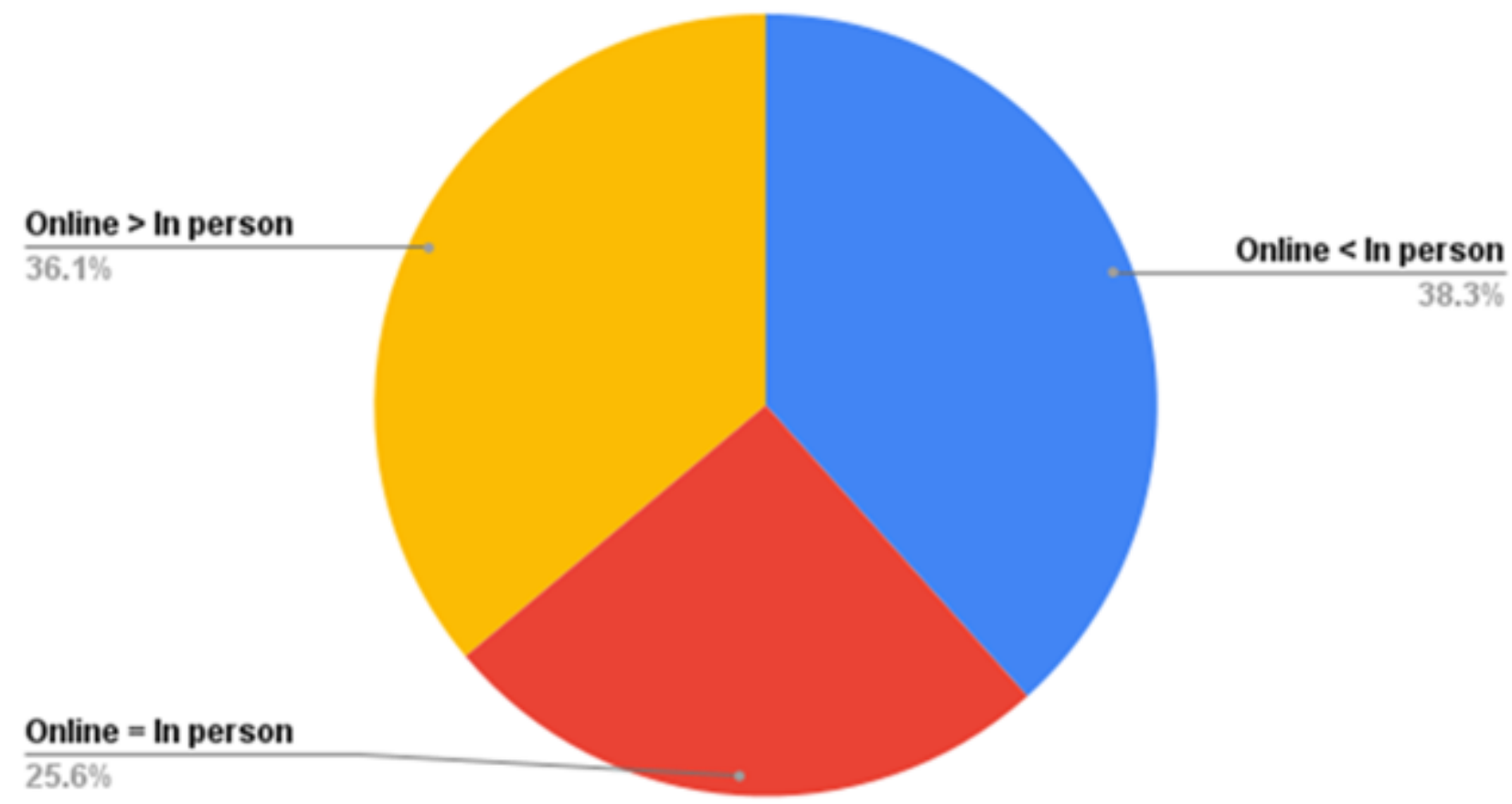

Figure 4

Ability to understand the contents of a teaching sessions

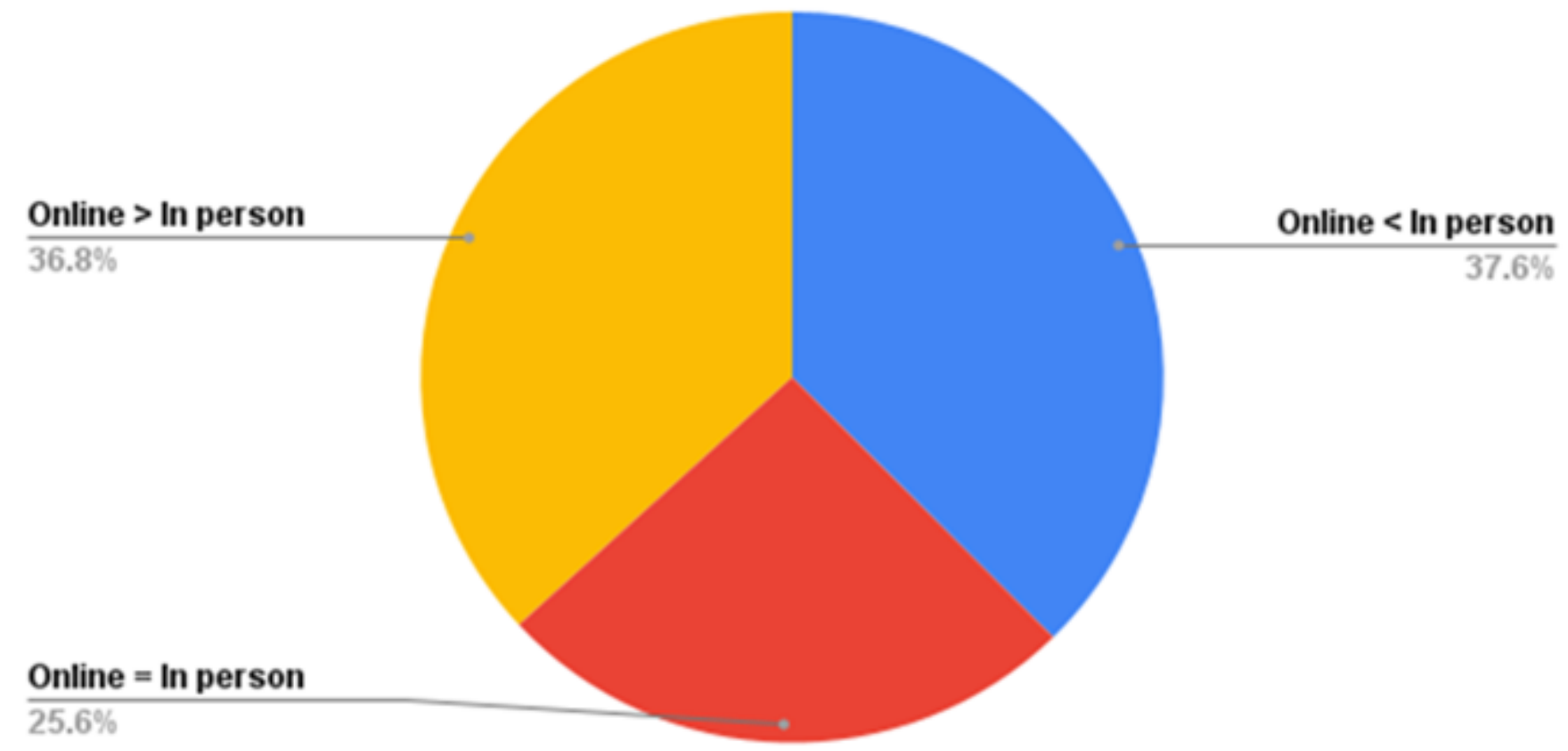

Figure 5

Active student participation during teaching activity 


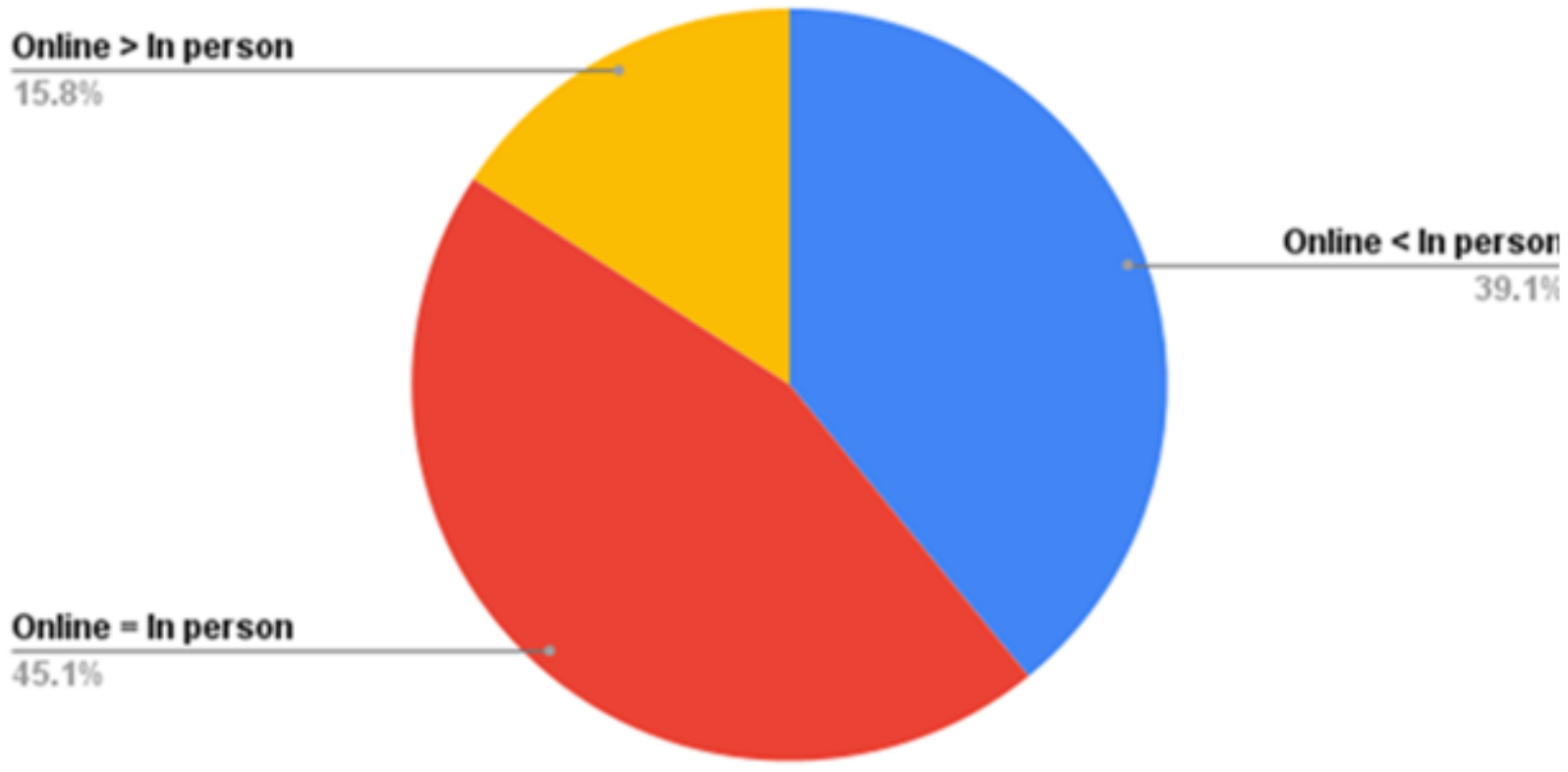

Figure 6

Opinion on teachers' enthusiasm

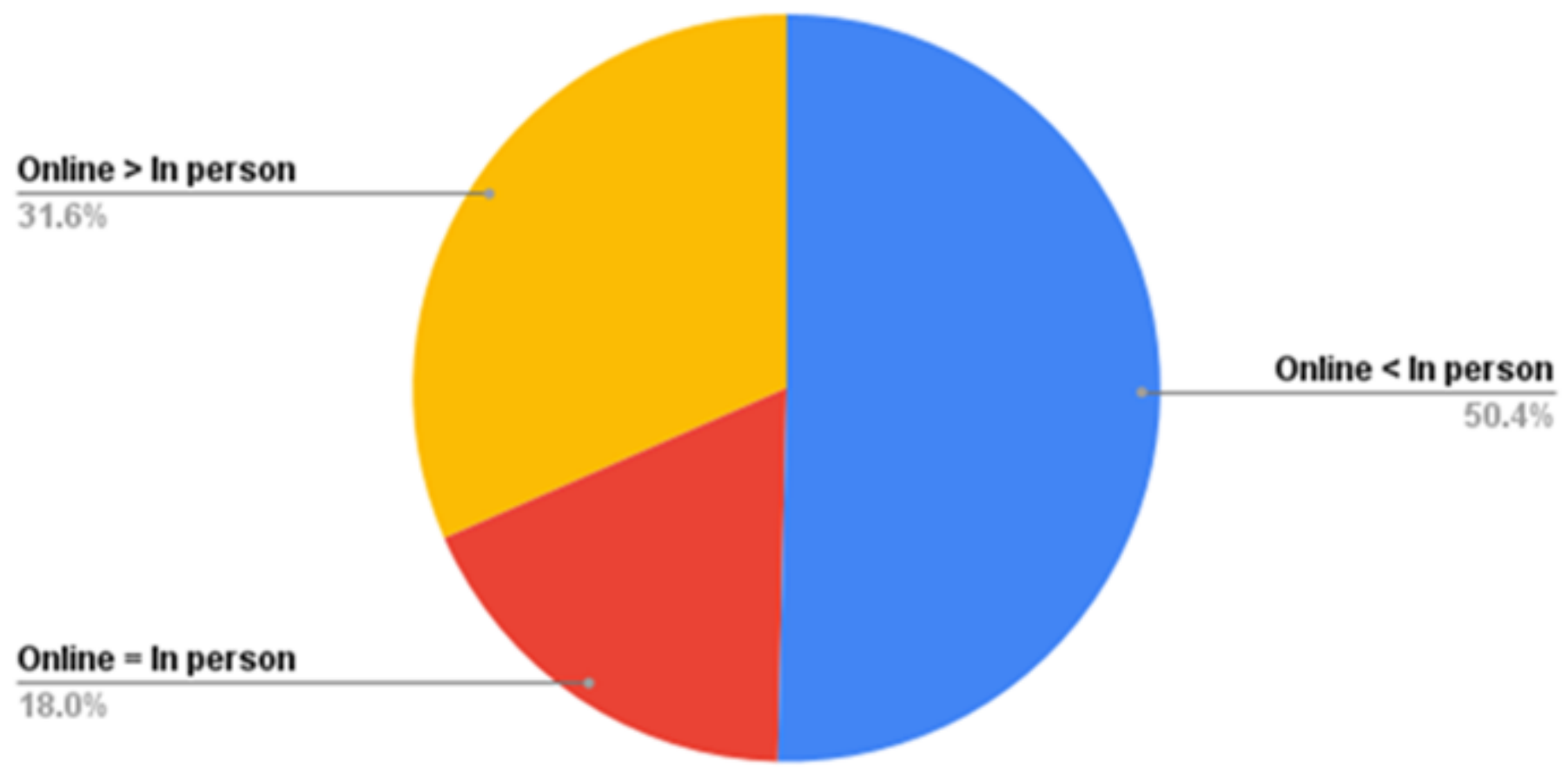

Figure 7

Overall impression Comparing 'in-person' and 'online' teaching 


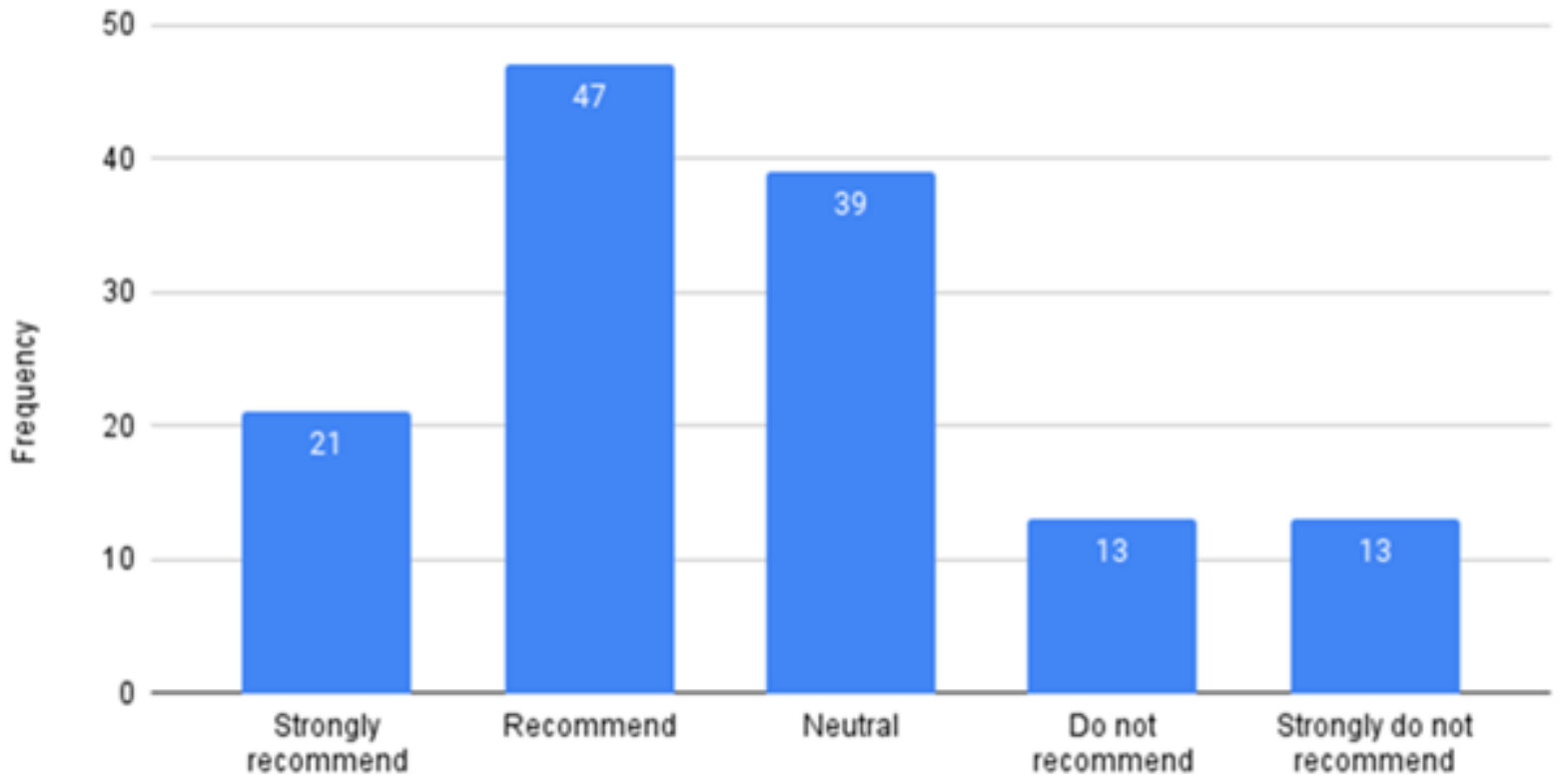

Rcommendation on continuation of future online teaching

\section{Figure 8}

Student opinion on continuing online teaching after the epidemic

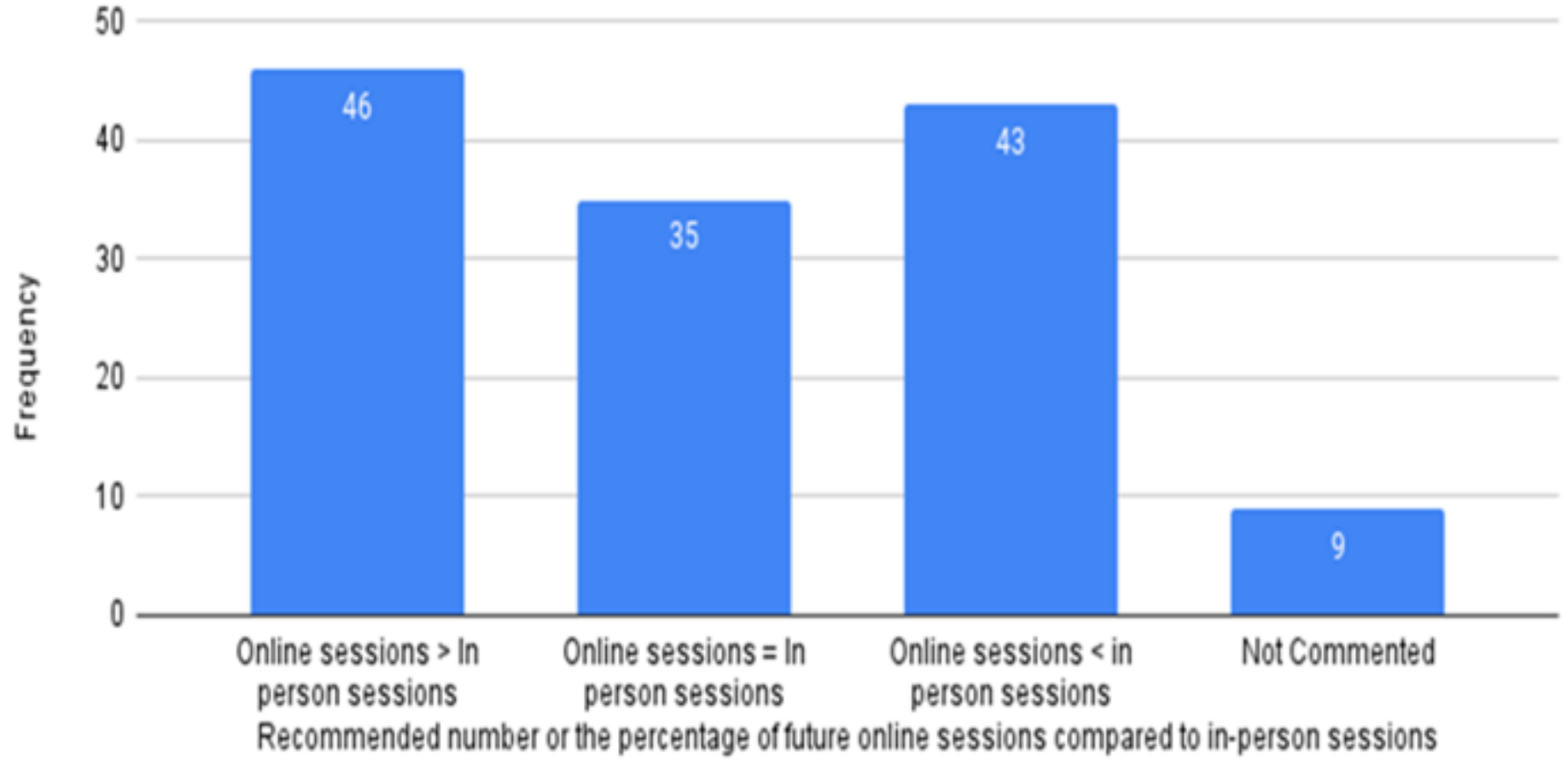

Figure 9

Preferred proportion between online and in-person teaching 